\title{
Work Ability Index (WAI) values in a sample of the working population in Poland
}

\author{
Grzegorz Juszczyk ${ }^{1, A-F}{ }^{\oplus}$, Aleksandra Izabela Czerw ${ }^{2,3, B-F} \oplus$, Urszula Religioni ${ }^{4, C-F} \oplus$,

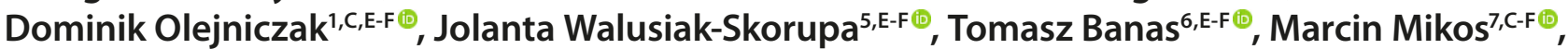 \\ Anna Staniszewska ${ }^{8, E-F}$ (6) \\ ${ }^{1}$ Department of Public Health, Medical University of Warsaw, Warsaw, Poland \\ ${ }^{2}$ Department of Health Economics and Medical Law, Medical University of Warsaw, Warsaw, Poland \\ ${ }^{3}$ Department of Economic and System Analyses, National Institute of Public Health - NIH, Warsaw, Poland \\ ${ }^{4}$ Collegium od Business Administration, Warsaw School of Economics, Warsaw, Poland \\ ${ }^{5}$ Department of Occupational Diseases and Toxicology Clinic, Institute of Occupational Medicine, Lodz, Poland \\ ${ }^{6}$ Department of Gynaecology and Oncology, Jagiellonian University Medical College, Krakow, Poland \\ ${ }^{7}$ Institute of Public Health, Jagiellonian University Medical College, Krakow, Poland \\ ${ }^{8}$ Department of Experimental and Clinical Pharmacology, Medical University, Warsaw, Poland \\ A - Research concept and design, B - Collection and/or assembly of data, C - Data analysis and interpretation, \\ $D$ - Writing the article, E - Critical revision of the article, $F$ - Final approval of article
}

Juszczyk G, Czerw Al, Religioni U, Olejniczak D, Walusiak-Skorupa J, Banas T, Mikos M, Staniszewska A. Work Ability Index (WAI) values in a sample of the working population in Poland. Ann Agric Environ Med. 2019; 26(1): 78-84. doi: 10.26444/aaem/91471

\section{Abstract}

Introduction. Ability to work is most often defined as a relationship between a person's resources and requirements specific to a particular type of work. It is the result of interaction between job requirements in terms of physical and mental strain, capabilities and skills of the employee, as well as his/her health condition and own evaluation of functioning in a given organizational and social situation.

Objective. The primary objective of the study was to evaluate the current value of the Work Ability Index (WAI) in a sample of employees in Poland.

Materials and method. The study sample was selected purposefully from 422,000 employees covered by the largest occupational health provider in Poland. The standard WAI questionnaire provided by CAWI (Computer-Assisted Web Interview) methodology was voluntary and completed anonymously by 688 employees within 12 months $(0.16 \%$ response rate). The results were statistically analyzed using the Pearson's chi-squared test and correlation coefficient, independentsample $T$ test and one-way analysis of variance $(p<0.05)$.

Results. It was found that the average value of WAI was $37.5 \pm 7.7$, and $37 \%$ of the participants represented low to moderate ability to work. The results showed no significant correlation between the WAI value and its 7 compounds and demographic variables. Nonetheless, a dependency between WAI level and industrial branch was observed.

Conclusions. Subjects with moderate and low WAI (1/3 of the study population) had particular indications to implement prophylactic actions, especially for the health care employees and civil servants, whose ability to work may be subject to accelerated deterioration.

\section{Key words}

work ability, occupational health services, work capacity evaluation, work performance, occupational therapists

\section{INTRODUCTION}

The ageing of society constitutes a challenge not only for the health care sector, but also for the economy in general. Eurostat data indicates that people over 60 will account for about 25\% of Poland's population in 2020 [1]. This is a phenomenon which will continue to escalate in the years to come, and it is estimated that by 2030 , the percentage of people over 60 years of age will amount to nearly $30 \%$. A consequence of this phenomenon is the shortage of a labour force due to the fact that ability to work decreases with age. Consequently, efforts to maintain the ability to work of current and future employees is of key importance. For that purpose, at the beginning of 1980s in Finland, the concept of maintaining the ability to work was created and the Finnish

Address for correspondence: Aleksandra Izabela Czerw, Department of Economic and System Analyses, National Institute of Public Health - NIH, Warsaw, Poland e-mail: aczerw@pzh.gov.pl

Received: 11.05.2017; accepted: 22.05.2018; first published: 28.09.2018
Institute of Occupational Health (FIOH) played a pioneering role by creating a tool for employee's self-evaluation of their ability to work [2].

Ability to work is most often defined as the relationship between a person's resources and requirements specific to a particular type of work. This is the result of interaction between job requirements in terms of physical and mental strain, capacities and skills of the employee, as well as his/ her health condition and own evaluation of functioning in a given organizational and social situation [3]. Despite the fact that ability to work depends on many and varied factors, it is considered that an employee's physical and mental health is the key factor.

Excellent ability to work is closely related to the possibility to increase the quality of work, improve quality of life and well-being among employees, thereby decreasing the likelihood of their early retirement, decreasing absenteeism and presenteeism (ineffective presence at work), as well as increasing motivation and productiveness in employees of all ages [4]. 
The Finnish concept of Promoting and Maintaining Workability (PMWA) is equivalent to Workplace Health Promotion (WHP). The PMWA model assumes that other factors, along with health, impact an employee's ability to work, such as his/her competences, relations with others, the health environment or psycho-social factors, and promoting ability to work, improves both the well-being of individual employees and effectiveness of the functioning of their workplace.

The instrument which is used most frequently for evaluating ability to work is the Work Ability Index (WAI), developed in the Finnish Institute of Occupational Health in Helsinki. It takes into account specific psychosocial and physical factors related to performing a given type of work, as well as the employee's mental and physical resources and his/her health condition [5].The WAI is used to evaluate employees' ability to work in terms of the type of work performed and the related strains. This makes it possible to compare abilities to work depending on the employee's age.

WAI is determined on the basis of a questionnaire completed by the employee; the questionnaire covers 7 dimensions:

1) an individual's current work ability compared with their lifetime best;

2) work ability in relation to the demands of the job;

3) number of diagnosed illnesses;

4) estimated impairment due to diseases/illnesses or limiting conditions;

5) amount of sick leave taken during the last 12 months;

6) own prognosis of work ability in 2 years' time;

7) estimate of their mental resources [6].

The WAI allows for a self-evaluation of individual factors and factors associated with the performance of a specific type of work, affecting work ability to varying degrees. This kind of information makes it possible to forecast permanent disability among employees or future absenteeism related to illness. Numerous studies have shown that low ability to work increases the risk of long-term sick leaves, early retirement, incapacity to a given type of work and disability [7]. The Work Ability Index provides employees and employers with information which should be taken into account in the development of methods and tools to improve work efficiency, both on the individual and organizational level.

\section{OBJECTIVE}

The primary aim of the study was to assess the current WAI value in a broad population group of employees using the Internet. The secondary objective was to indicate the dependencies between selected socio-demographic factors (age, gender, region of the employer's main location, type of predominant work activity and industrial branch), and health-related variables (the WAI value, absenteeism, self-evaluation of the work ability forecast, evaluation of mental resources). An additional aim was also to assess the applicability of such an electronic based data collection method in occupational medicine practice.

\section{MATERIALS AND METHOD}

Study group. The study was carried out by using the CAWI (Computer-Assisted Web Interview) method. The group was selected purposefully - in order to obtain access to a large group of potential employees, a standard WAI questionnaire in the Polish translation according to Pokorski [8] was placed on the web site of the largest private health care provider offering preventive health care to over $1.2 \mathrm{mln}$ Polish employees from among $16 \mathrm{mln}$ total working population (7.5\%). The institution granted access to their customers free of charge and ethical approval was not required since participants filled the questionnaire anonymously and no personal data were collected in the study. A questionnaire which guaranteed anonymity was made available in the 'www. luxmed.pl' domain during the period 15 November 2012 - 14 November 2013 (12 months) along with instructions for the users. All participants were asked to read the information explaining that all provided data will be anonymous, used only for scientific purposes, and to confirm their consent. During that period, the website was visited by 422,000 unique users who could complete the survey by selecting a special window containing an invitation to participate. The sample's representativeness was estimated based on a comparison of the structure of professions declared by the respondents in relation to the branch-specific employment structure of people working in the national economy in Poland, according to the data of the National Statistical Office (GUS) for the period in which the study was performed.

WAI questionnaire. The first part of the questionnaire contained demographic information such as gender, age, region of the employer's main location, type of predominant work activity, and branch of industry. The second part consisted of the validated WAI comprising 7 items with different scoring range (in parenthesis below)

1. current work ability compared with the lifetime best (0-10);

2. work ability in relation to the demands of the job (2-10);

3. number of current diseases diagnosed by a physician and patient (1-7);

4. estimated work impairment due to diseases (1-6);

5. sick leave during the past year (1-5);

6. personal prognosis of work ability 2 years from now (1.4 or 7$)$;

7. mental resources, referring to the worker's life in general, both at work and during leisure time (1-4).

WAI is than calculated by summing-up the estimated points for each item. The total WAI score ranged from $7-49$ points, and the scores were categorized into 4 levels as poor (7-27), moderate (28-36), good (37-43) and excellent (44-49). Subjects with a WAI score of 36 or lower were classified as having low work ability, and subjects with a WAI score of 37 and above were classified as having satisfactory work ability $[9,10]$.

Statistical methods. To meet the aims of the study, the statistical analysis applied to interval variables included the independent $\chi 2$ tests, one-way analysis of variance (ANOVA) and t-test for independent samples to compare means. To assess the linear correlation between variables, Pearson's correlation coefficient was used. However, estimated work impairment due to diseases, sick leave during the past 
year, personal prognosis of work ability 2 years from now, were measured on an ordinal scale. Analyses concerning these variables were performed with the use of Spearman's rho correlation coefficients and Mann-Whitney $U$ test. Significance level was considered at $\mathrm{p}<0.05$. Statistical data analysis was performed using Statistica 10 software.

\section{RESULTS}

Characteristics of the study group. There were 688 participants in the study out of 422,000 (estimated response rate $-0.16 \%$ ). Detailed data of selected socio-demographic variables are presented in Table 1 . The respondents were mostly women (495; 72\%). The average age for both genders was $35.5 \pm 10.6$ years; the youngest participant in the study was 16 years old, the oldest 77 . Respondents most often declared to be residents of larger cities with populations over 200 thousand (67.4\%). Villages were the least frequently selected as place of residence (8.6\%).

The majority of study participants declared to be whitecollar workers without subordinates ( $60.7 \%$ of cases), $19.3 \%$ of respondents held managerial positions ( $17.5 \%$ women; $24.2 \%$ men). Slightly more than $16 \%$ of respondents were blue-collar workers, and $3.7 \%$ of respondents (predominantly men) had a mobile job where most of the time is spent in means of transportation. The largest group of respondents worked in services $(38.4 \%)$, followed by sales (14.7\%), health care $(14.7 \%)$, manufacturing (10.9\%) and administration (10.6\%). Women worked predominantly in services (37.6\%) and health care (17.3\%), while men in services (40.5\%) and manufacturing $(21.6 \%)$.

WAI general. The first stage of data analysis included finding differences in the WAI value among particular employee groups, identified based on age, gender, place of residence, sector and type of work performed. Due to missing data, particular parameters were calculated for respondents who provided complete responses.

Average WAI in the study sample of population - 37.5 \pm 7.7 , median - 39 (Tab. 2). It should be noted that WAI was calculated based only on questionnaires not lacking data $(\mathrm{N}=530)$. Minimal WAI value $-12(0.2 \%)$, maximal WAI value -49 (0.9\%). Given the WAI value, $11.5 \%$ employees were qualified to the low work ability group, $25.9 \%$ had moderate ability to work, $39.3 \%$ of respondents evaluated their ability to work as good and $23.4 \%$ as excellent.

Dimensions of WAI/Current work ability compared with lifetime best. In the questionnaire the respondents also declared current work ability compared with their lifetime best (scale of $0-10$, where 0 means complete incapacity to work and 10 - the best ability to work). The average evaluation of current work ability for all employees was 7.9 \pm 2.3 . 10 was the value indicated most often (30\% of respondents). 0 was not been indicated by any respondent.

Work ability in relation to demands of the job. Estimated on the basis of the respondents' answers to 2 questions: 'How would you rate your current ability to work in relation to the physical effort required for your work?' and 'How would you rate your current ability to work in relation to the mental requirements of your work?'

The possible range was $2-10$, where 2 - means very bad and 10 - very good. The average value of the work ability in relation to the requirements of the profession was $8.3 \pm 1.6$. The highest value (10) was indicated by $29.8 \%$ of respondents. The lowest value (3) was indicated by $0.6 \%$ of respondents.

Number of current diseases diagnosed by a physician and patient. The average number of diseases indicated by respondents was $3.4 \pm 3.6$. The largest number of employees

Table 1. Characteristics of the study group $(\mathrm{N}=688)$

\begin{tabular}{|c|c|c|c|c|c|}
\hline Name of a variable & Categories & Total & Men & Women & $\mathrm{p}$ \\
\hline Age (years) & $\mathrm{M} \pm \mathrm{SD}$ & $35.5 \pm 10.6$ & $35.2 \pm 11.2$ & $35.1 \pm 10.4$ & $\begin{array}{c}t(678)=1.08 \\
p=0.282\end{array}$ \\
\hline \multirow{5}{*}{ Place of residence } & No data & $8(1.2 \%)$ & $0(.0 \%)$ & $6(1.2 \%)$ & \multirow{5}{*}{$\begin{array}{c}\chi^{2}(3)=8.32 \\
p=0.040\end{array}$} \\
\hline & City $>200$ thousand inhabitants & $464(67.4 \%)$ & $126(67.0 \%)$ & $336(67.9 \%)$ & \\
\hline & City of $51-200$ thousand inhabitants & $92(13.4 \%)$ & $17(9.0 \%)$ & $74(14.9 \%)$ & \\
\hline & City $<50$ thousand inhabitants & $65(9.4 \%)$ & $24(12.8 \%)$ & $41(8.3 \%)$ & \\
\hline & Village & $59(8.6 \%)$ & $21(11.2 \%)$ & $38(7.7 \%)$ & \\
\hline \multirow{5}{*}{$\begin{array}{l}\text { Type of a } \\
\text { predominant } \\
\text { work activity }\end{array}$} & Office work without any subordinates & $418(60.7 \%)$ & $95(50.5 \%)$ & $320(64.6 \%)$ & \multirow{5}{*}{$\begin{array}{c}\chi^{2}(4)=24.42, \\
p=0.001\end{array}$} \\
\hline & Physical work only during daytime & $71(10.3 \%)$ & $18(9.6 \%)$ & $52(10.5 \%)$ & \\
\hline & Physical shift work, including night shifts & $41(6.0 \%)$ & $13(6.9 \%)$ & $28(5.7 \%)$ & \\
\hline & Mobile work, when the most of the working time an employee drives a vehicle & $25(3.7 \%)$ & $16(8.5 \%)$ & $9(1.8 \%)$ & \\
\hline & Managers & $133(19.3 \%)$ & $46(24.2 \%)$ & $86(17.5 \%)$ & \\
\hline \multirow{7}{*}{ Type of a branch } & Construction & $20(2.9 \%)$ & $11(5.7 \%)$ & $9(1.8 \%)$ & \multirow{7}{*}{$\begin{array}{c}\chi^{2}(7)=60.39, \\
p=0.001\end{array}$} \\
\hline & Education and science & $51(7.4 \%)$ & $5(2.6 \%)$ & $46(9.3 \%)$ & \\
\hline & Trade & $101(14.7 \%)$ & $25(12.9 \%)$ & $76(15.4 \%)$ & \\
\hline & Health care & $100(14.7 \%)$ & $14(7.3 \%)$ & $86(17.3 \%)$ & \\
\hline & Manufacturing & 75 (10.9\%) & $41(21.6 \%)$ & $34(6.9 \%)$ & \\
\hline & Mining & $4(.6 .0 \%)$ & $0(.0 .0 \%)$ & $4(0.8 \%)$ & \\
\hline & Services & 264 (38.4\%) & 78 (40.5\%) & $186(37.6 \%)$ & \\
\hline
\end{tabular}


Table 2. Values of WAI and its 7 dimensions

WAI

WAI Total, M+SD

Dimension 1. Current work ability compared with the lifetime best, $M \pm S D$.

2. Work ability in relation to the demands of the job, $M \pm S D$.

$7.9 \pm 2.3$

3. No. of current diseases diagnosed by a physician and patient, $M \pm S D$.

$8.3 \pm 1.6$

4. Estimated work impairment due to diseases.

$\mathrm{n}(\%)$.

There is no hindrance/l have no diseases.

$3.4 \pm 3.6$

I am able to do my job, but it causes some symptoms.

I must sometimes slow down my work pace or change my work methods.

$218(31.7)$

I must often slow down my work pace or change my work methods.

Because of my disease, I feel I am able to do only part-time work.

In my opinion, I am entirely unable to work.

5. Sick leave during the past year

$\mathrm{n}(\%)$

none at all

$10-24$ days

6. Personal prognosis of work ability 2 years from now.

Do you believe that - from the standpoint of your health - you will be able to do your current job two years from now?, n (\%)

Mental resources, referring to ife in general, both at work and during leisure time, $M \pm S D$

Table 3. Health problems declared by study participants $(\mathrm{N}=688)$

\begin{tabular}{|c|c|c|c|c|c|c|}
\hline \multirow{2}{*}{ Health problem } & \multicolumn{3}{|c|}{ Diagnosed by a physician } & \multicolumn{3}{|c|}{ Present according to a patient's opinion } \\
\hline & $\mathrm{N}$ & $\%$ & WAI $(\mathrm{M} \pm \mathrm{SD})$ & $\mathrm{N}$ & $\%$ & WAI $(M \pm S D)$ \\
\hline Back injury & 117 & 17.0 & $33.2 \pm 6.3$ & 117 & 17.0 & $37.2 \pm 7.4$ \\
\hline Arm or hand injury & 76 & 11.1 & $34.4 \pm 6.2$ & 62 & 9.0 & $34.4 \pm 7.8$ \\
\hline Leg/foot injury & 123 & 17.9 & $33.8 \pm 7.3$ & 52 & 7.6 & $37.8 \pm 6.9$ \\
\hline Disorder of the upper back or cervical spine, recurrent pain & 160 & 23.3 & $33.4 \pm 7,2$ & 163 & 23.7 & $37.2 \pm 7.4$ \\
\hline Rheumatoid arthritis & 24 & 3.5 & $28.8 \pm 8.3$ & 31 & 4.5 & $35.8 \pm 9.1$ \\
\hline Hypertension (or high blood pressure) & 113 & 16.4 & $33.8 \pm 8.0$ & 33 & 4.8 & $35.8 \pm 9.9$ \\
\hline Obesity & 68 & 9.9 & $32.1 \pm 8.3$ & 84 & 12.2 & $37.4 \pm 7.6$ \\
\hline Diabetes & 38 & 5.5 & $35.1 \pm 9.8$ & 10 & 1.5 & $36.4 \pm 3.9$ \\
\hline Bronchial astma & 46 & 6.7 & $33.9 \pm 7.1$ & 10 & 1.5 & $34.7 \pm 8.6$ \\
\hline Mental disease or severe mental health problem (e.g. severe depression) & 31 & 4.5 & $28.8 \pm 9.1$ & 23 & 3.3 & $33.0 \pm 6.1$ \\
\hline Slight mental disorder or problem (e.g. slight depression, tension, anxiety, insomnia) & 88 & 12.8 & $31.0 \pm 8.1$ & 161 & 23.4 & $35.7 \pm 7.6$ \\
\hline Problems or injury to hearing & 37 & 5.4 & $32.4 \pm 7.2$ & 50 & 7.3 & $33.6 \pm 8.6$ \\
\hline Visual disease or injury (other than refractive error) & 65 & 9.4 & $32.2 \pm 8.3$ & 14 & 2.0 & $34.7 \pm 5.8$ \\
\hline Malignant tumour (cancer) & 14 & 2.1 & $37.4 \pm 6.2$ & 3 & 0.4 & $31.0 \pm 2.0$ \\
\hline
\end{tabular}

(18.7\%) did not indicate any diseases, while $4 \%$ respondents indicated more than 10 diseases (Tab. 3). The table shows that patients with rheumatoid arthritis, mental disease or severe mental health problem (e.g. severe depression) diagnosed by a physician had the lowest WAI score (28.8). Bearing in mind health problems according to a patient's opinion, the lowest WAI scores were obtained by patients with malignant tumour (cancer) (31.0).

Estimated work impairment due to diseases. Around 2\% of the respondents claimed that due to their disease or injury they suffered from complete incapacity to work. $31.7 \%$ of respondents declared no problems with their capacity to work. Roughly $35 \%$ of respondents claimed to have the capacity to work, but that activity caused the occurrence of disease symptoms.19.8\% of respondents admitted that due to their disease or injury, they often had to reduce their pace of work, and $6.2 \%$ of respondents declared that they were forced to rest frequently or change the mode in which the work was performed. About $6 \%$ of respondents claimed that they were able to work only part-time.

Sick leave during the past year. The majority of respondents had spent 25 - 99 days and 100 - 365 days on sick leave 
during the past year (35.3\% and $34.7 \%$, respectively). Over $16 \%$ of respondents were off work because of a health problem during $10-24$ days, and $8.7 \%$ at the most 9 days. $5.1 \%$ of respondents indicated that they had not been on sick leave during the past year.

Personal prognosis of work ability 2 years from now. $82.1 \%$ of respondents believed that over the next 2 years they would be able to continue their current work. Over 14\% employees indicated that they were not certain whether their current health status allow them to continue work. 3\% of respondents claimed that it was very unlikely that they would be able to continue their current work in the upcoming 2 years.

Mental resources, referring to the workers life in general, both at work and during leisure time. Mental resources necessary to perform work were evaluated on the basis of 3 questions: 'Have you recently found pleasure in the performance of everyday activities?' 'Have you recently been active and zestful?' and 'Have you recently been hopeful when thinking of the future?' The highest evaluation of mental resources (4) was reported by $12.1 \%$ of respondents and the lowest (1) by $15.7 \%$. The mean value was $2.4 \pm 0.9$.

Correlation between the WAI value and its 7 dimensions and demographic variables. Table 4 shows all association between WAI general (including 7 dimensions) and independent variables, e.g. age, region of employer's main location, type of predominant work activity and industrial branch.

The results obtained showed that the WAI and its 7 dimensions (current work ability compared with the lifetime best, work ability in relation to demands of the job, number of current diseases diagnosed by a physician, estimated work impairment due to diseases, sick leave during the past year, personal prognosis of work ability 2 years from now, and mental resources, referring to the workers life in general, both at work and during leisure time) were not dependent on gender or place of residence (in all cases $\mathrm{p}>0.05$ ).

There was a relationship between work ability and requirements of the profession and branches $(\mathrm{p}=0.02)$. The

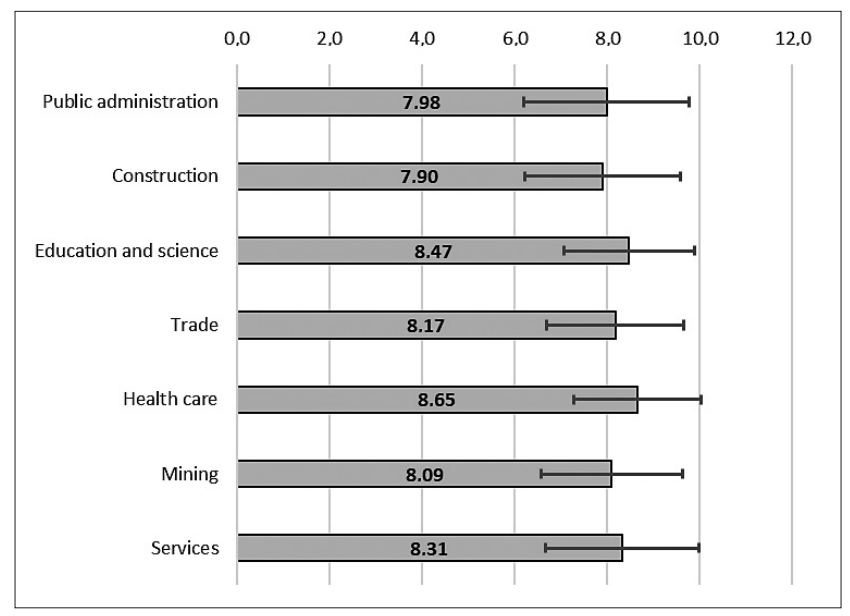

Figure 1. Average WAI values in relation to requirements of the profession in various branches $(\mathrm{N}=688)$

highest work ability value (10) was indicated most often by employees active in education and science $(39.0 \%$ of the sample) and trade (34.9\% of the sample), and the lowest by health care employees ( $4 \%$ of the sample) (Fig. 1).

Absenteeism due to sickness was connected with the branch in which the respondents worked $(\mathrm{p}=0.02)$. Health care employees spent the biggest number of days on sick leave ( $10.7 \%$ were on sick leave for over 3 months), followed by public administration employees (up to $8.8 \%$ of the sample). Industry employees were on sick leave least frequently (over $50 \%$ had not had even one day on sick leave in the previous year), followed by construction workers (47.1\% had not been on sick leave in the previous year).

The duration of sick leave was not dependent on gender, age, place of residence or province (in all cases $\mathrm{p}>0.05$ ). However, age correlated negatively to estimated work impairment due to diseases and personal prognosis of work ability 2 years from now.

Estimated work impairment due to diseases and personal prognosis of work ability 2 years from now were lowest in the group of patients performing day physical work, and highest in the group of people performing office work

Table 4. Correlation between WAI total and its 7 dimensions and independent variables

\begin{tabular}{|c|c|c|c|c|c|}
\hline \multirow[b]{2}{*}{ Dependent variables } & \multicolumn{5}{|c|}{ Independent variables } \\
\hline & Age & Sex & $\begin{array}{c}\text { Place } \\
\text { of residence }\end{array}$ & $\begin{array}{c}\text { Type of a predominant } \\
\text { work activity }\end{array}$ & $\begin{array}{c}\text { Type } \\
\text { of a branch }\end{array}$ \\
\hline WAl total & $\begin{array}{l}r=0.175 \\
p=0.082\end{array}$ & $\begin{array}{l}t=1.15 \\
p=0.250\end{array}$ & $\begin{array}{l}F=1.11, \\
p=0.346\end{array}$ & $\begin{array}{l}F=2.36, \\
p=0.080\end{array}$ & $\begin{array}{l}F=1.28, \\
p=0.256\end{array}$ \\
\hline Dimension 1. Current work ability compared with lifetime best & $\begin{array}{l}r=-0.107 \\
p=0.112\end{array}$ & $\begin{aligned} t & =0.71 \\
p & =0.480\end{aligned}$ & $\begin{array}{l}F=0.58, \\
p=0.631\end{array}$ & $\begin{array}{l}F=1.03, \\
p=0.393\end{array}$ & $\begin{array}{l}F=1.41 \\
p=0.200\end{array}$ \\
\hline 2. Work ability in relation to demands of the job & $\begin{array}{l}r=0.050 \\
p=0.606\end{array}$ & $\begin{aligned} t & =0.73 \\
p & =0.873\end{aligned}$ & $\begin{array}{l}F=-0.25, \\
p=0.326\end{array}$ & $\begin{array}{l}F=1.08, \\
p=0.533\end{array}$ & $\begin{array}{l}F=2.81 \\
p=0.020\end{array}$ \\
\hline 3. No. of current diseases diagnosed by a physician and patient & $\begin{array}{l}r=-0.178 \\
p=0.065\end{array}$ & $\begin{array}{c}t=1.67 \\
p=0.104\end{array}$ & $\begin{array}{l}F=1.14, \\
p=0.333\end{array}$ & $\begin{array}{l}F=0.88, \\
p=0.474\end{array}$ & $\begin{array}{l}F=1.06 \\
p=0.386\end{array}$ \\
\hline 4. Estimated work impairment due to diseases & $\begin{array}{c}\rho=-0.083, \\
p=0.031\end{array}$ & $\begin{array}{c}\mathrm{U}=42101.5 \\
\mathrm{p}=0.121\end{array}$ & $\begin{array}{l}\chi^{2}=4.26 \\
p=0.235\end{array}$ & $\begin{aligned} \chi^{2} & =36.47, \\
p & =0.001\end{aligned}$ & $\begin{array}{c}\chi^{2}=14.64, \\
p=0.023\end{array}$ \\
\hline 5. Sick leave during the past year & $\begin{array}{l}\rho=-0.012 \\
p=0.747\end{array}$ & $\begin{array}{c}U=42140.5 \\
p=0.066\end{array}$ & $\begin{array}{l}\chi^{2}=2.16 \\
p=0.540\end{array}$ & $\begin{array}{l}\chi^{2}=18.75 \\
\mathbf{p}=0.001\end{array}$ & $\begin{array}{l}\chi^{2}=3.78 \\
p=0.707\end{array}$ \\
\hline 6. Personal prognosis of work ability 2 years from now & $\begin{array}{c}\rho=-0.109, \\
p=0.004\end{array}$ & $\begin{array}{c}U=45441.0 \\
p=0.787\end{array}$ & $\begin{array}{l}\chi^{2}=1.41, \\
p=0.703\end{array}$ & $\begin{array}{l}\chi^{2}=37.44 \\
\mathbf{p}=0.001\end{array}$ & $\begin{array}{l}\chi^{2}=9.88 \\
p=0.130\end{array}$ \\
\hline 7. Mental resources, referring to life in general, both at work and during leisure time & $\begin{array}{l}r=0.030 \\
p=0.429\end{array}$ & $\begin{array}{l}t=1.59 \\
p=0.111\end{array}$ & $\begin{array}{l}F=0.37, \\
p=0.777\end{array}$ & $\begin{array}{l}F=2.03, \\
p=0.089\end{array}$ & $\begin{array}{l}F=1.90 \\
p=0.062\end{array}$ \\
\hline
\end{tabular}


without subordinates or having managerial positions. Sick leave during the past year was highest in the group of people in managerial positions.

Estimated work impairment due to diseases was lowest in the group of patients working in public administration, education and science or trade, and highest in the group of patients working in health care.

\section{DISCUSSION}

Pilot studies conducted by Makowiec-Dąbrowska et al. using the WAI questionnaire showed that it to be a very useful method which makes it possible to identify determinants of ability to work in a broad context, and not limited to health aspects [11]. Based on results obtained in a group of 189 employees (men), the study outlined an interesting picture of a worker who is fully capable to work. He was a young employee with good housing conditions, had enough sleep on working days (without night shifts), ate properly, was not overweight, did not abuse alcohol and had normal blood pressure. He performed averagely burdensome work, but also worked overtime. Further studies have shown a negative correlation between the ability to work and age (especially in men), as well as a greater dynamism in WAI decrease in people performing mainly white-collar work, which may be related to the declared higher level of stress in that group [5]. A very valuable conclusion indicates that a low WAI is not a reflection of the high level of aggravating factors at work and rather poor tolerance of such factors.

In the sample analysed in the presented study, the lowest average WAI was among health care employees, which is an observation identical with the conclusions drawn from the study evaluating WAI levels among nurses in 10 European countries [12]. The WAI value was the lowest among Polish participants, and also decreased most dynamically in relation to the increase in age. Nurses had the worst prognosis in terms of maintaining ability to work, which is confirmed by Italian studies of 867 hospital workers representing different professions, where this group exhibited the most significant decline in WAI with increasing work experience [13]. Furthermore, it became apparent that women demonstrated a generally lower WAI than men [11], which is explained by the relationship of gender-related life roles and a greater burden in terms of family responsibilities [14]. This was reflected in a study of nurses (both women and men), in which subjective deterioration of work ability measured by WAI was associated with the total workload exclusively in women ([15]. However, in this study, no difference was found in the WAI value between men and women.

The health problems most often declared in the study group were disorders and diseases of the musculoskeletal system, which inevitably involved ensuring access to appropriate treatment and rehabilitation benefits exceeding the scope of preventative health care of employees. A study assessing the correlation between the WAI level with the need for rehabilitation benefits showed that people with a low WAI level, during the 12 months following the evaluation, were 4.6 times more likely to become unemployed, and 12.2 times more in risk of long-term absenteeism due to sickness, compared to individuals with good and excellent WAI [16].

The authors suggest that the WAI level $\leq 37$ is a clear predictor of the employee's rehabilitation needs. Interesting conclusions have also been provided by a study conducted on Danish production workers, where the correlation between the WAI level and functional pain in the musculoskeletal system was investigated [17]. It was observed that experiencing pain reduces productivity, but it does so to a greater extent in the group of people with a good WAI, rather than in the case of people with moderate work ability.

In the presented study, a statistically significant correlation between extended absenteeism due to sickness was observed only in selected lines of business, but was not confirmed for variables such as age, gender or current WAI level. The impact of WAI on the level of absenteeism in other studies is clearly differentiated - one Finnish study analysed the frequency of sick leaves over 9 days taken during one year, compared to a baseline WAI measurement for 31-year-olds [18]. Men with a low WAI faced a 3.6 times greater risk of at least one such sick leave than people with excellent WAI (in women, the risk was 6.2 times greater, respectively). On the other hand, Ahlstrom et al, stated that an increased WAI correlated positively with the process of rehabilitation and return to work in women on long-term sick leaves, mainly suffering from diseases of the musculoskeletal system (48\%) and mental disorders (40\%) [19].

In the current study sample, the average WAI was 37.4, and the group of people with good and excellent WAI accounted collectively for $62.6 \%$, which is a result close to the parameters obtained in studies conducted on similar groups (young mainly white-collar workers employed in services). In a much smaller group of 50 administrative employees, the average WAI was 40.5 , and $78 \%$ of respondents had a good or excellent WAI, while only $2 \%$ of respondents had a low WAI [20].

Despite attempts to replace the WAI with a simpler measurement tool which could be used in practice by occupational physicians, WAI remains an important tool for predicting changes in an employee's health condition over time. One study considered the possibility of using only one item of the questionnaire - the question of current work ability compared with one's lifetime best in a scale of $0-10$, instead of the full WAI questionnaire [21]. Results indicate a statistically relevant compatibility of the response to that question with the general WAI, and suggest that it could be used for initial screening purposes. However, this method was not confirmed as effective for forecasting total or partial loss of work ability in a group of blue-collar workers; in this case, the much greater predictive value of the standard WAI questionnaire was proved [22].

The presented study obviously has its limitations, e.g. the study sample differs from the distribution of the Polish employees among branches - with underrepresentation of manufacturing and overrepresentation of services. The chosen method of data collection (CAWI) requires access to a computer and the Internet in order to participate in the study, and may exclude people at the age closer to retirement age, and with assumingly more deteriorated health. Moreover, when comparing declarations regarding length of absenteeism due to sickness made by the respondents and the data collected by the Social Insurance Institution (ZUS) [23], a substantial difference between results of the study and general data for Poland can be observed. The average length of declared absenteeism per year was 3.9 day, while that value in 2013was as high as 13.2 day for the whole Polish population. The inability to verify the declarations with actual data on absenteeism provided by employers makes it impossible to 
draw conclusions about the ability to work in terms of WAI and the frequency and length of employees' sick leaves.

Finally, the results of the study offer potential practical applications for occupational therapist and other professionals involved in workplace health care activities. WAI can be used to define risk groups for advanced preventive activities, mainly for employees with a score of less than 37. Such groups can be further divided to targeted activities related to currently declared health problems (according to the study results the most likely would be musculoskeletal, vison and metabolic disorders). At risk groups may be further examined in order to refer each person to an individual prevention scheme, extending the scope of activities addressed to all employees. Secondly, WAI enables evaluation of an employees long-term risk of work ability deterioration when a process of monitoring sick leaves of employees is applied, and the company establishes its internal thresholds for high sickness absenteeism. Employees with higher than average scores may be asked to additionally complete the WAI questionnaire in order to spot earlier the need for prevention and long-term risk mitigation.

\section{CONCLUSIONS}

- The WAI evaluation suggests that only almost $60 \%$ of respondents considered their ability to work as at least very good.

- A population evaluation in terms of WAI is most useful when carried out within the framework of preventive care of employees, as the participation rate in the Internet survey was low.

- The people with particular indications for being subject to targeted preventive actions are those with moderate and low WAI, which constitute over $1 / 3$ of the sample. In terms of different lines of business, the fastest decline in work ability was typical for health care and administration employees. The WAI is not a sufficient tool for forecasting the level of absenteeism due to sickness without supplementing the data declared by the patient with objective data about the level of absenteeism provided by the employer.

\section{Acknowledgements}

The authors would like to thank LUX MED Ltd., Poland, for granting them access to the www.luxmed.pl website, and for the free programming of the research questionnaire.

\section{REFERENCES}

1. Eurostat. Work and health in the EU. A statistical portrait: Data 19942002. Luxembourg: Office for Official Publications of the European Communities; 2004

2. Ilmarinen J. The work ability index (WAI). Occup Med (Lond). 2007; 57: 160 .
3. Makowiec-Dąbrowska T, Koszada-Włodarczyk T, Bortkiewicz A, Gadzicka E, Siedlecka J, Jóźwiak Z, et al. Zawodowe i pozazawodowe determinanty zdolności do pracy. Med Pr. 2008; 59(1): 9-24 [in Polish].

4. Wężyk A, Merecz D. Prezentyzm - (nie)nowe zjawisko w środowisku pracy Med Pr. 2013; 64(6): 847-61 [in Polish].

5. Van den Berg TI, Elders LA, de Zwart BC, Burdorf A. The effects of work-related and individual factors on the work ability index: A systematic review. Occup Environ Med. 2009; 66(4): 211.

6. Ahlstrom L, Grimby-Ekman A, Hagberg M, Dellve L. The work ability index and single-item question: associations with sick leave, symptoms, and health - a prospective study of women on long-term sick leave. Scand J Work Environ Health. 2010; 36(5): 405.

7. Salonen P, Arola H, Nygard CH. Factors associated with premature departure from working life among ageing food industry employees. Occup Med (Lond). 2003; 53: 65-8.

8. Pokorski J. Indeks zdolności do pracy - wersja polska. Cracow: Jagiellonian University Medical College; 1998 [in Polish].

9. Mazloumi A, Rostamabadi A, Nasl Saraji G, Rahimi Foroushani A. Work ability index (WAI) and its association with psychosocial factors in one of the petrochemical industries in Iran. J Occup Health. 2012; 54: $112-8$.

10. Sanne B, Mykletun A, Moein BE, Dahl AA, Tell GS. Farmers are at risk for anxiety and depression: the Hordaland Health Study. Occup Med (Lond). 2004; 54: 92-100.

11. Makowiec-Dąbrowska T, Strusińska E, Bazylewicz-Walczak B, RadwanWłodarczyk Z, Koszada-Włodarczyk W. Zdolność do pracy - nowe podejście do sposobu oceny. Med Pr. 2000; 51(4): 317-33 [in Polish].

12. Camerino D, Conway PM, Van der Heijden BI, Estryn-Behar M, Consonni D, Gould D, et al. Low-perceived work ability, ageing and intention to leave nursing: a comparison among 10 European countries. J Adv Nurs. 2006; 56(5): 542-52.

13. Costal G, Sartori S, Bertoldo B, Olivato D, Ciuffa V, Antonacci G. The Work Ability Index in hospital workers. G Ital Med Lav Ergon. 2005; 27(3): 355-8.

14. Musshauser D, Bader A, Wildt B, Hochleitne M. The impact of sociodemographic factors vs. gender roles on female hospital workers' health: do we need to shift emphasis? J Occup Health. 2006; 48: 383-91.

15. Rotenberg L, Portela LF, Banks B, Griep RH, Fischer FM, Landsbergis P. A gender approach to work ability and its relationship to professional and domestic work hours among nursing personnel. Appl Ergon. 2008; 39(5): 646-52.

16. Bethge M, Radoschewski FM, Gutenbrunner C. The Work Ability Index as a screening tool to identify the need for rehabilitation: longitudinal findings from the Second German Sociomedical Panel of Employees. J Rehabil Med. 2012; 44(11): 980-7.

17. Sell L, Lund HL, Holtermann A, Søgaard K. The interactions between pain, pain-related fear of movement and productivity. Occup Med (Lond). 2014; 64(5): 376-81.

18. Kujala V, Tammelin T, Remes J, Vammavaara E, Ek E, Laitinen J. Work ability index of young employees and their sickness absence during the following year. Scand J Work Environ Health. 2006; 32(1): 75-84.

19. Ahlstrom L, Hagberg M, Dellve L. Workplace Rehabilitation and Supportive Conditions at Work: A Prospective Study. J Occup Rehabil. 2013; 23: 248-60.

20. Costa AF, Puga-Leal R, Nunes IL. An exploratory study of the Work Ability Index (WAI) and its components in a group of computer workers. Work. 2011; 39(4): 357-67.

21. El Fassi M, Bocquet V, Majery N, Lair ML, Couffignal S, Mairiaux P. Work ability assessment in a worker population: comparison and determinants of Work Ability Index and Work Ability score. BMC Public Health. 2013; 8: 305.

22. Roelen CA, van Rhenen W, Groothoff JW, van der Klink JJ, Twisk JW, Heymans MW. Work ability as prognostic risk marker of disability pension: single-item work ability score versus multi-item work ability index. Scand J Work Environ Health. 2014; 40(4): 428-31.

23. Karczewicz E, Sikora A. Absencja chorobowa w 2013 roku. Warsaw: National Social Insurance Institution; 2014 [in Polish]. 